\title{
PENGEMBANGAN KAWASAN INDUSTRI TELEMATIKA DALAM UPAYA MENDORONG DAYA SAING REGIONAL (KASUS KOTA CIMAHI)
}

\author{
The Development of ICT Industry Cluster to Drive its Regional \\ Competitiveness (Case of Cimahi City)
}

\section{Lia Warlina $^{1}$, Rifiati Safariah ${ }^{1}$ dan Andri Heryandi ${ }^{2}$}

\begin{abstract}
Abstrak: Industri telematika merupakan industri yang sangat berkembang karena kebutuhan dan ketergantungan manusia terhadap teknologi informasi semakin tinggi. Salah satu kawasan industri telematika yang ada di Indonesia adalah di Kota Cimahi. Oleh karena itu tujuan penelitian ini adalah untuk mengidentifikasi karakteristik dan kompetensi inti dari industri telematika/ ICT, mengidentifikasi faktor internal dan eksternal yang mempengaruhi daya saing, serta mengidentifikasi faktor kunci apa yang dapat dikembangkan untuk mendorong daya saing regional berdasrkan skenario yang terpilih. Survey data primer dilakukan untuk memperoleh informasi tentang karakteristik industri telematika, kompetensi inti, serta faktor internal daya saing. Survey data sekunder dilakukan untuk memperoleh data faktor eksternal daya saing. Selanjutnya dilakukan analisis prospektif untuk menyusun skenario untuk pengembangan kawasan industri telematika di Cimahi. Hasil penelitian menunjukkan bahwa kompetensi inti dari industri telematika adalah pada animasi, film dan sistem informasi. Faktor kunci yang dapat dikembangkan untuk mendorong daya saing adalah (1) kualitas jasa telekomunikasi; (2) ketersediaan tenaga kerja; (3) daya tanggap terhadap perubahan dan kebaruan; (4) Etika bisnis; (5) regulasi yang mengatur industri ICT/ telematika.
\end{abstract}

\section{Kata kunci: industri telematika, daya saing regional, Kota Cimahi}

Abstract: The ICT industry is developing greatly because human dependency of information technology increases rapidly. One of ICT industry cluster in Indonesia is in Cimahi City. The research objectives were to identify general characteristics of ICT industry and its core competence, and also to acquire internal and external factors of competitiveness; and also to identify key factors that could be developed to drive regional competitiveness of ICT industry in Cimahi City based on chosen scenario. Primary data survey conducted to obtain information regarding, ICT industry characteristics, core competence of ICT industry and internal factor of competitiveness. Meanwhile, secondary data survey was conducted to obtain information regarding external factors of competitiveness. Prospective analysis was conducted to build scenario in developing ICT industry cluster in Cimahi City. Research result showed that core competence of ICT industry were animation, film and information system. Key factors to drive reginal competitiveness of ICT industry cluster were telecommunication service quality, skillful labor availability, responsiveness on change and innovation; business ethics and ICT industry regulation.

Keywords: ICT industry, regional competitiveness, Cimahi City

\footnotetext{
${ }^{1}$ Program Studi Perencanaan Wilayah \& Kota Universitas Komputer Indonesia

${ }^{2}$ Program Studi Teknik Informatika Universitas Komputer Indonesia
} 


\section{PENDAHULUAN}

Daya saing merupakan syarat keharusan agar industri mampu bersaing pada pasar domestik dan pasar global. Saat ini Indonesia tengah berupaya melakukan peningkatan daya saing yang dapat mendukung pengembangan industri agar tidak semakin tertinggal dengan negara lain. Salah satu upaya untuk itu adalah dengan ditetapkan Masterplan Percepatan dan Perluasan Pembangunan Indonesia (MP3EI) dengan tiga strategi utama yaitu (1) Pengembangan potensi ekonomi melalui koridor ekonomi, (2) Penguatan konektivitas nasional, dan (3) Penguatan sumberdaya manusia dan ilmu pengetahuan nasional (Kementerian Koordinator Bidang Perekonomian, 2011). Salah satu kegiatan ekonomi utama yang menjadi fokus pengembangan dalam MP3EI tersebut adalah adalah industri telematika atau information communication technology (ICT).

Industri telematika merupakan industri yang sangat berkembang terutama di negara maju. Hal ini terjadi karena kebutuhan dan ketergantungan manusia terhadap teknologi informasi yang semakin tinggi. Berdasarkan hasil penelitian yang dilakukan oleh International Telecommunication Union (2015) tampak bahwa jumlah pengguna ICT secara global terus meningkat selama satu dekade ini. Pemilik telepon genggam secara global meningkat tajam dari sekitar 20\% pada tahun 2001 menjadi 96,8\% pada tahun 2015 . Demikian pula dengan pengguna internet, pada tahun 2001 hanya berjumlah dibawah $10 \%$ pada tahun 2015 diperkirakan akan mencapai 43,4\%. Sedangkan pelanggan jaringan pita lebar (mobile) yang baru mulai pada tahun 2007 dan diperkirakan pada tahun 2015 akan mencapai $47,2 \%$. Peningkatan pelanggan jaringan pita lebar kabel tidak sedinamis untuk pita lebar mobile. Meskipun jaringan pita lebar kabel ini telah dimulai sejak tahun 2001, pada tahun 2015 diperkirakan sekitar 10 orang dari 100 penduduk yang berlangganan. Keadaan yang lebih drastis terjadi pada pelanggan telepon kabel yang mengalami penurunan dari tahun 2001 sejumlah hampir 20\% menjadi sekitar 14\% pada tahun 2015. Keadaan tersebut disajikan pada Gambar 1.

Berbeda dengan kondisi global, kondisi di Indonesia pada tahun 2014, tercatat untuk pengguna internet ada 88,1 juta orang atau sekitar 34,9\% penduduk. Jumah ini lebih kecil dari pengguna internet secara global yang berjumlah $40 \%$. Sementara pengguna intenet didominasi oleh penduduk di wilayah barat Indonesia dengan jumlah sekitar 78,5\% (APJII dan Puskakom, 2015). Sementara itu, jumlah pelanggan telepon selular di Indonesia yaitu sebesar 126,2 pelanggan per 100 penduduk. Sedangkan jumlah pelanggan telepon kabel hanya sebesar 11,7 per 100 orang penduduk (World Economic Forum, 2015).

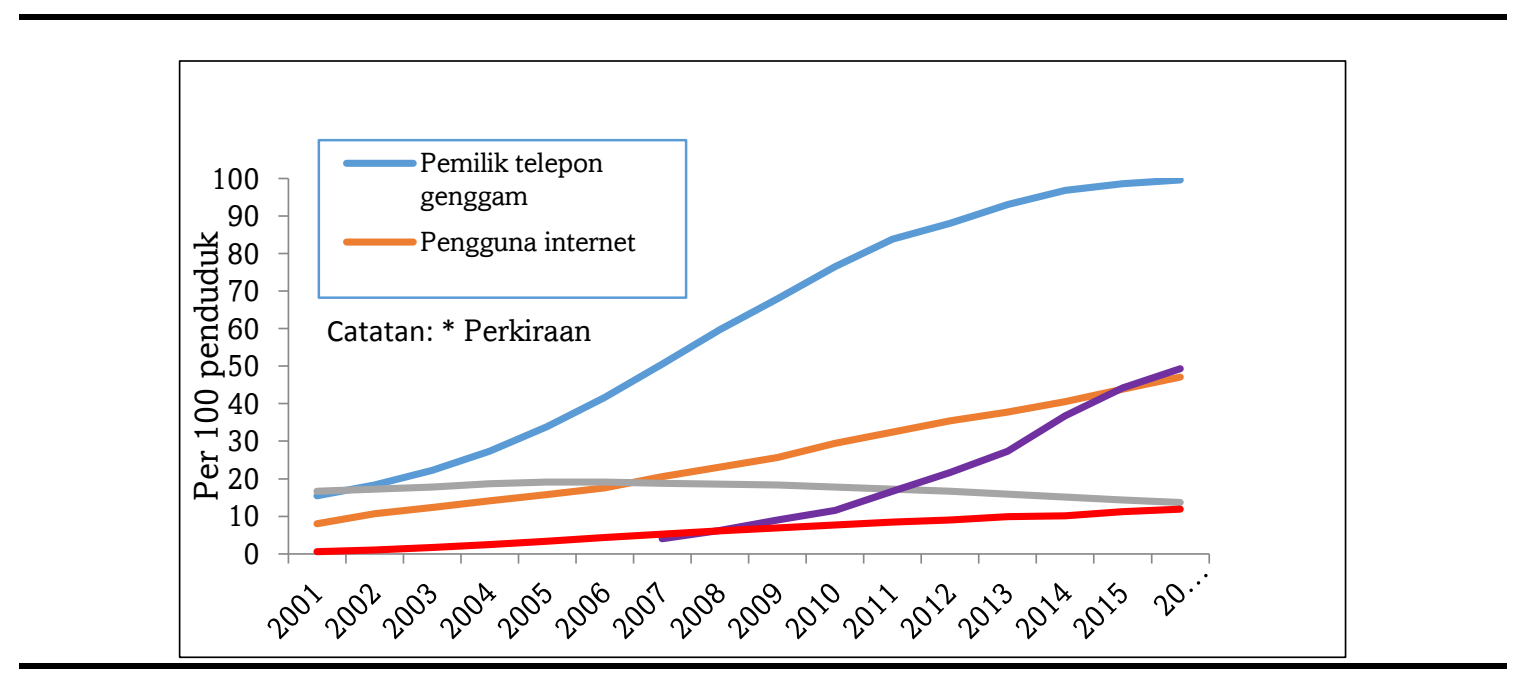

Gambar 1. Perkembangan ICT secara Global tahun 2001-2016 (ITU, 2016) 
Mastel (2005) menyatakan bahwa agar industri telematika nasional mempunyai daya saing, hal yang perlu dilakukan adalah dengan (1) pengembangan industri telematika lebih terencana, mempunyai visi yang jelas, agar dapat dibuat rencana pengembangan kompetensi masing-masing; (2) pertumbuhan di sisi industri telematika diimbangi oleh kecepatan tumbuh industri perangkat dalam negeri; dan (3) industri perangkat akan memiliki kapasitas yang mampu menjadi pendukung utama pertumbuhan telematika nasional.

Daya saing regional adalah kemampuan perekonomian wilayah untuk mengoptimalkan aset asli wilayahnya untuk bersaing dan berhasil dalam pasar nasional dan global untuk beradaptasi dan merubah keadaan pasar tersebut (Martin, 2013). Sedangkan, Lengyel (2003) menyimpulkan tentang daya saing (competitiveness) sebagai berikut: (a) daya saing menunjukkan notasi kompleks yang dapat diaplikasikan pada seluruh unit ekonomi dasar (perusahaan, sektor, wilayah, negara, region), (b) memfokuskan pada dua kategori yang terukur yaitu: pendapatan dan lapangan kerja, (c) partisipasi dari kompetisi internasional dan ekonomi terbuka, atau lebih memperhatikan produk dan jasa yang dapat dipasarkan dalam kompetisi global, (d) untuk pendapatan yang relatif tinggi, tetapi tidak ada spesifikasi bagaimana pendapatan tersebut terdistribusikan diantara pemilik modal dan karyawan (e) angka pertumbuhan lapangan kerja, yang berkaitan dengan kebijakan sosial, tetapi tidak merefleksikan struktur lapangan kerja (kualifikasi dari angkatan kerja).

Porter (1990) menyatakan penentu daya saing suatu negara (determinants of competitive advantage) dapat digambarkan dalam suatu diagram seperti pada Gambar 2 berikut. Konsep dari Porter tersebut banyak dikembangkan untuk konsep daya saing regional, seperti oleh Martin (2013) bahwa unsur daya saing adalah keterkaitan antara (1) faktor kondisi (faktor input), (2) kondisi demand (permintaan), (3) persaingan, struktur dan strategi perusahaan dan (4) industri pendukung dan terkait suplai industri.

Kondisi faktor atau faktor input adalah faktor produksi seperti sumberdaya dan infrastruktur serta modal. Sumberdaya meliputi sumberdaya manusia (SDM), dan sumberdaya alam (SDA). Infrastruktur dapat berupa infrastruktur fisik, informasi, ilmu pengetahuan dan teknologi serta administrasi. Semakin banyak faktor input yang dimiliki daya saing makin tinggi. Kondisi demand (permintaan) adalah permintaan pasar terhadap produk dan jasa. Faktor ini berupa jumlah pembeli, pertumbuhan permintaan serta kecanggihan permintaan. Makin maju masyarakat permintaan akan meningkat dari tingkat lokal ke global. Industri pendukung dan terkait suplai industri berupa adanya industri pesaing dan adanya industri pendukung. Agar terjadi efisiensi dan sinergi perlu adanya sharing teknologi. Faktor persaingan struktur dan strategi perusahaan berkaitan dengan strategi dan struktur dari perusahaan dan tujuan perusahaan. Faktor ini berkaitan pula dengan kebanggaan nasional serta komitmen yang berkelanjutan.

Beberapa penelitian tentang pengembangan kawasan industri ICT/ telematika telah dilakukan di beberapa negara seperti India dan Kanada. Pengembangan kawasan industri ICT di India berhasil dilakukan di Bangalore dan Hyderabad. Menurut Balatchandirane (2007) keberhasilan Klaster IT di India (di Bangalore dan Hyderabad) merupakan akibat dari: besarnya peran pemerintah dalam penyediaan insentif serta dalam mengatasi kendala dalam pengembangan industri IT, kualitas sumberdaya manusia bidang IT, adanya penyediaan lokasi yang tepat, adanya keunggulan lokasi, adanya kompetisi dengan klaster IT lainnya.

Beberapa penelitian tentang pengembangan kawasan industri ICT/ telematika telah dilakukan di beberapa negara seperti India dan Kanada. Pengembangan kawasan industri ICT di India berhasil dilakukan di Bangalore dan Hyderabad. Menurut Balatchandirane (2007) keberhasilan Klaster IT di India (di Bangalore dan Hyderabad) merupakan akibat dari: besarnya peran pemerintah dalam penyediaan insentif serta dalam mengatasi kendala dalam pengembangan industri IT, kualitas sumberdaya manusia bidang IT, adanya penyediaan lokasi yang tepat, adanya keunggulan lokasi, adanya kompetisi dengan klaster IT lainnya. 


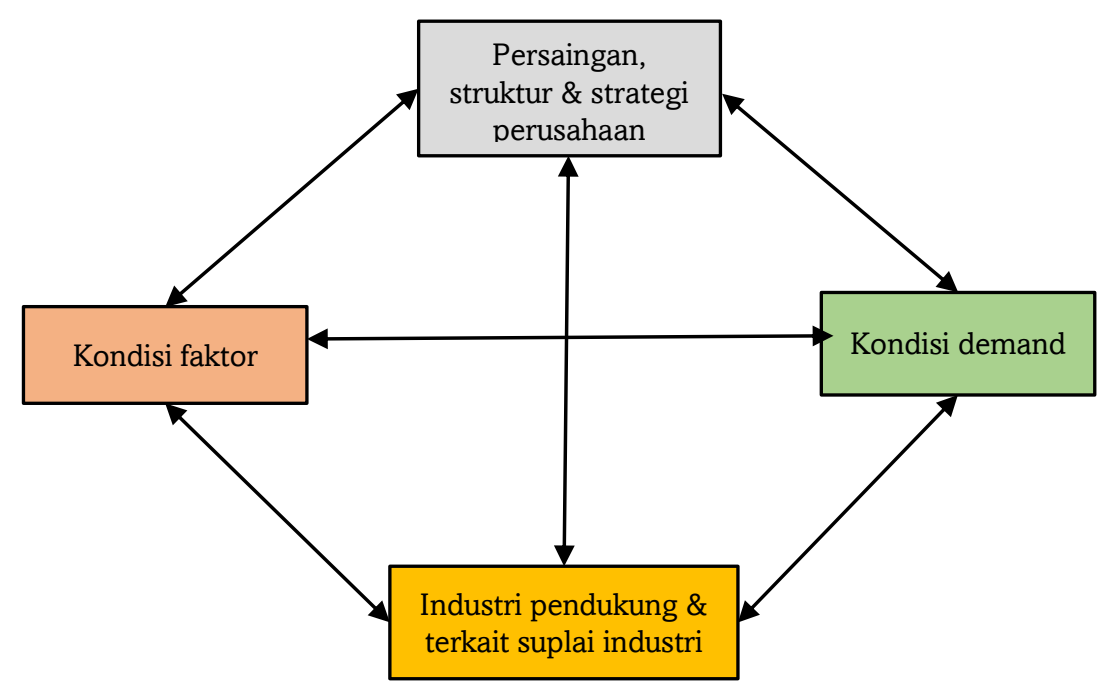

Gambar 2. The Diamond of Competitive Advantage (Porter, 1990)

Beberapa penelitian tentang pengembangan kawasan industri ICT/ telematika telah dilakukan di beberapa negara seperti India dan Kanada. Pengembangan kawasan industri ICT di India berhasil dilakukan di Bangalore dan Hyderabad. Menurut Balatchandirane (2007) keberhasilan Klaster IT di India (di Bangalore dan Hyderabad) merupakan akibat dari: besarnya peran pemerintah dalam penyediaan insentif serta dalam mengatasi kendala dalam pengembangan industri IT, kualitas sumberdaya manusia bidang IT, adanya penyediaan lokasi yang tepat, adanya keunggulan lokasi, adanya kompetisi dengan klaster IT lainnya.

Sedangkan keberhasilan pengembangan kawasan industri telematika di Kanada adalah akibat adanya kebijakan. Kebijakan yang ditetapkan untuk pengembangan industri ICT adalah pengembangan SDM melalui pembangunan infrastruktur penelitian, dan melalui investasi dalam bidang pendidikan. Di Kanada pada klaster ICT terdapat keterbukaan terhadap pasar eksternal dan berorientasi ekspor.Selain itu adanya faktor non lokal yaitu dinamika pasar dan jaringan global yang meliputi suplier, konsumen dan kompetitor industri ICT. Klaster ICT yang berhasil di Kanada adalah yang selain berhasil di level regional juga secara efektif terhubung dengan jaringan global (Lucas, Sands \& Wolfe, 2009).

Hansen \& Serin (2010) menyatakan bahwa pengembangan kawasan industri melalui aglomerasi kawasan tergantung pula pada faktor eksternal. Faktor eksternal yang mendukung aglomerasi industri ICT adalah infrastruktur yang maju, aksesibitas jalan, airport dan transportasi publik yang terpercaya, infrastruktur yang dikembangkan dengan baik seperti koneksi internet dan telepon yang handal, infrastruktur pendidikan yang unggul, universitas dan sekolah yang baik memegang peranan penting, kemampuan pembiayaan, masyarakat yang kreatif dan memiliki jiwa entreprenership, perangkat hukum yang baik dalam melindungi hak kekayaan intelektual serta kepastian hukum perpajakan, jaringan yang kuat dalam aspek pemasaran.

Menurut Mulyadi (2013) upaya peningkatan daya saing kawasan industri adalah dengan, meningkatkan peran pemerintah dalam mengembangkan kawasan industri, membangun kawasan industri yang terintegrasi dengan sektor lain termasuk perumahan dan 
rumah sakit untuk buruh, membangun kawasan industi yang fokus pada satu komoditas tertentu, dan membangun kemampuan SDM dan pusat innovasi.

Berdasarkan hal tersebut diatas, maka penelitian untuk pengembangan kawasan industri telematika di Indonesia sebagai upaya mendorong daya saing penting dilakukan. Salah satu kota di Indonesia yang memiliki kawasan industri telematika/ ICT adalah Kota Cimahi. Oleh sebab itu penelitian dilakukan dengan studi kasus Kota Cimahi.

Salah satu tools dalam membangun model pengembangan adalah metode Analisis Prospektif dari Godet (2000). Metode ini mengikuti langkah-langkah berikut: penetapan tujuan, identifikasi faktor-faktor, analisis pengaruh antar factor, membuat keadaan suatu factor, membangun dan memilih skenarion dan implikasi dari scenario. Oleh karena itu, dalam penelitian ini, tools yang digunakan adalah analisis prospektif. Analisis prospektif digunakan untuk menemukan faktor-faktor kunci yang dapat dikembangan dari industri telematika/ ICT untuk mendorong daya saing regional. Berdasar pada penjelasan sebelumnya maka perumusan masalah penelitian ini adalah karakteristik dan kompetensi inti dari industri telematika Kota Cimahi, faktor internal dan eksternal yang mempengaruhi daya saing industri telematika Kota Cimahi, faktor kunci yang dapat digunakan berdasarkan skenario terpilih untuk pengembangan industri telematika yang berdaya saing di Kota Cimahi

Adapun yang menjadi tujuan dari penelitian ini adalah sebagai berikut mengidentifikasi karakteristik dan kompetensi inti dari industri telematika Kota Cimahi, mengidentifikasi faktor internal dan eksternal yang mempengaruhi daya saing industri telematika Kota Cimahi, mengidentifikasi faktor kunci serta menetapkan skenario untuk pengembangan industri telematika yang berdaya saing di Kota Cimahi.

\section{METODE PENELITIAN}

Pengumpulan data dilakukan dengan cara survey data primer data sekunder. Hasil dari survey tersebut digunakan sebagai input ke dalam Software Analisis Prospektif. Analisis prospektif digunakan untuk menentukan faktor kunci dan menyusun skenario untuk pengembangan kawasan industri telematika.

Survey data primer dilakukan dengan wawancara langsung yaitu interview secara mendalam kepada pimpinan Cimahi Creative Association (CCA) dan pimpinan perusahaan di lingkungan CCA. Survey data primer dilakukan untuk memperoleh informasi tentang karakteristik industri telematika dan kompetensi inti dari industri telemtika yang ada di Cimahi, serta faktor internal daya saing industri telematika berdasarkan Porter's Diamond, faktor kondisi (faktor input), kondisi demand (permintaan), strategi, struktur dan rivalry perusahaan; serta industri pendukung yang berkaitan.

Survey data sekunder dilakukan untuk memperoleh informasi tentang kondisi lingkungan eksternal dari industri telematika di Kota Cimahi. Identifikasi dilakukan untuk melihat kondisi lingkungan eksternal yang meliputi infrastruktur fisik, infrastruktur ICT, entrepreneurship, perangkat hukum, jaringan pemasaran, pembiayaan dan infrastruktur pendidikan.

Hasil dari survey data primer berupa data internal faktor daya saing. Hasil dari survey data sekunder berupa faktor eksternal dari industri telematika. Faktor-faktor tersebut dinilai tingkat pengaruh dan tingkat ketergantungannya. Dalam menentukan tingkat pengaruh nilai yang dimasukkan ke dalam software analisis prospektif adalah nilai yang diberikan adalah nilai dari para peneliti.

Hasil dari nilai pengaruh dan ketergantungan berupa grafik pengaruh antar faktor. Faktor kunci adalah faktor yang tingkat pengaruh dan ketergantungannya bernilai di atas 1 (satu). Selanjutnya ditetapkan keadaan dari faktor kunci tersebut. Faktor-faktor kunci yang telah ditemukan dibuat keadaannya yang digunakan untuk membangun dan memilih skenario; serta menyusun implikasi dari skenario pengembangan. 


\section{HASIL DAN PEMBAHASAN}

\section{Karakteristik dan kompetensi inti industri telematika di Kota Cimahi}

Karakteristik umum dari industri telematika di Kota Cimahi disajikan pada Tabel 1. Berdasarkan Tabel 1, usia perusahaan masih relatif muda, kurang dari sepuluh tahun. Dua dari tujuh perusahaan mendapat penerimaan (revenue) lebih dari satu milyar rupiah, sementara sisanya sekitar lima ratus juta rupiah atau kurang. Keuntungan tahunan dari perusahaan industri telematika yang ada di Kota Cimahi paling kecil adalah 30 juta rupiah pertahun dan yang tertinggi sebesar 400 juta rupiah. Jumlah tenaga kerja dari perusahaan industri telematika relatif sedikit yaitu berkisar 4 sampai dengan 11 orang. Hanya ada satu perusahaan dengan tenaga kerja reatif cukup banyak yaitu 40 orang. Produk yang dihasilkan dari industri telematika yang ada di Kota Cimahi adalah animasi, film dan sistem informasi. Klien atau konsumen dari industri ini adalah stasiun televisi, instansi pemerintah dan swasta. Kerja sama yang dilakukan oleh perusahaan industri telematika adalah dengan peusahaan lain.

Berdasarkan identifikasi karakteristik industri telematika dengan wawancara mendalam kepada para pengusaha dapat disimpulkan bahwa kompetensi inti dari industri telematika di Kota Cimahi adalah pada animasi, film dan sistem informasi. Khusus untuk kompetensi animasi, Kota Cimahi merupakan penyelenggara kegiatan Baros International Animation Festival. Hal ini juga sejalan dengan temuan dari Anandhita (2015) yang menyatakan bahwa kekuatan industri ICT atau telematika di Indonesia pada industri konten dan aplikasi.

Tabel 1. Karakteristik Umum industri Telematika Kota Cimahi

\begin{tabular}{|c|c|c|c|c|c|c|c|}
\hline \multirow[t]{2}{*}{ Responden } & \multirow[t]{2}{*}{$\begin{array}{l}\text { Berdiri } \\
\text { tahun }\end{array}$} & $\begin{array}{l}\text { Penerimaan } \\
\text { Tahunan }\end{array}$ & $\begin{array}{c}\text { Keuntungan } \\
\text { bersih } \\
\text { tahunan }\end{array}$ & $\begin{array}{c}\text { Jumlah } \\
\text { tenaga } \\
\text { kerja }\end{array}$ & \multirow[t]{2}{*}{ Produk } & \multirow[t]{2}{*}{ Konsumen } & \multirow[t]{2}{*}{ Kerjasama } \\
\hline & & (Juta rupiah) & (Juta rupiah) & (orang) & & & \\
\hline No.1 & 2011 & 1500 & 400 & 5 & $\begin{array}{l}\text { Animasi, } \\
\text { film }\end{array}$ & $\begin{array}{l}\text { Stasiun TV, } \\
\text { instansi } \\
\text { pemerintah, } \\
\text { swasta }\end{array}$ & $\begin{array}{c}\text { Perusahaan } \\
\text { lain }\end{array}$ \\
\hline No.2 & 2012 & 1500 & 400 & 40 & $\begin{array}{l}\text { Animasi, } \\
\text { film }\end{array}$ & $\begin{array}{l}\text { Stasiun TV, } \\
\text { instansi } \\
\text { pemerintah, } \\
\text { swasta }\end{array}$ & $\begin{array}{c}\text { Perusahaan } \\
\text { lain }\end{array}$ \\
\hline No.3 & 2009 & 200 & 100 & 4 & Animasi & $\begin{array}{l}\text { Instansi } \\
\text { pemerintah, } \\
\text { swasta }\end{array}$ & $\begin{array}{c}\text { Perusahaan } \\
\text { lain }\end{array}$ \\
\hline No.4 & 2011 & 500 & 100 & 7 & Animasi & $\begin{array}{l}\text { Instansi } \\
\text { pemerintah, } \\
\text { swasta }\end{array}$ & $\begin{array}{c}\text { Perusahaan } \\
\text { lain }\end{array}$ \\
\hline No.5 & 2011 & 200 & 50 & 4 & $\begin{array}{l}\text { Sistem } \\
\text { informasi }\end{array}$ & $\begin{array}{l}\text { Instansi } \\
\text { pemerintah, } \\
\text { swasta }\end{array}$ & $\begin{array}{c}\text { Perusahaan } \\
\text { lain }\end{array}$ \\
\hline No.6 & 2007 & 300 & 100 & 11 & $\begin{array}{l}\text { Animasi, } \\
\text { media } \\
\text { pembelajara } \\
\text { n interaktif, }\end{array}$ & $\begin{array}{l}\text { Instansi } \\
\text { pemerintah, } \\
\text { swasta }\end{array}$ & $\begin{array}{c}\text { Perusahaan } \\
\text { lain }\end{array}$ \\
\hline No.7 & 2014 & 80 & 30 & 4 & Animasi 2D & $\begin{array}{l}\text { Instansi } \\
\text { pemerintah, } \\
\text { swasta }\end{array}$ & $\begin{array}{c}\text { Perusahaan } \\
\text { lain }\end{array}$ \\
\hline
\end{tabular}

Sumber: Hasil survei, 2015

Faktor internal dan eksternal kondisi industri telematika

Faktor internal sebagai faktor daya saing Industri telematika/ ICT diperoleh dengan menggunakan Porter's Diamond yaiu berdasarkan pada (a) Faktor kondisi (faktor input), (b) Kondisi demand (permintaan), (c) Strategi, struktur dan rivalry perusahaan, (d) Industri pendukung yang berkaitan. 
Penilaian dilakukan oleh responden yaitu pimpinan perusahaan atau yang mewakilinya. Nilai tingkat pengaruh setiap komponen/ sub komponen/ atribut adalah 1 sampai 4. Nilai 1 mengandung arti sangat tidak berpengaruh, 2 berarti tidak berpengaruh. Sedangkan nilai 3 adalah berpengaruh dan 4 berarti sangat berpengaruh. Hasil kompilasi data tingkat pengaruh setiap komponen/ sub komponen dan atribut dijelaskan pada Tabel 2

Tabel 2. Tingkat Pengaruh Komponen Daya Saing di Industri Telematika Cimahi

\begin{tabular}{|c|c|c|c|c|c|c|c|}
\hline \multirow{2}{*}{ No. } & \multirow{2}{*}{ Faktor Internal } & \multicolumn{4}{|c|}{ Tingkat Pengaruh } & \multirow{2}{*}{$\begin{array}{c}\text { Jumlah } \\
\text { Responden }\end{array}$} & \multirow{2}{*}{ Rata-rata } \\
\hline & & 1 & 2 & 3 & 4 & & \\
\hline & FAKTOR KONDISI & & & & & & \\
\hline 1 & Ketersediaan tenaga kerja terampil & 0 & 0 & 0 & 7 & 7 & 4,00 \\
\hline 2 & Kemampuan manajerial & 0 & 0 & 1 & 6 & 7 & 3,86 \\
\hline 3 & Efisiensi dan produktivitas tenaga kerja & 0 & 0 & 3 & 4 & 7 & 3,57 \\
\hline 4 & Fasilitas dan pendidikan dan latihan & 0 & 1 & 3 & 3 & 7 & 3,29 \\
\hline 5 & Kualitas pelayanan infrastruktur & 0 & 0 & 3 & 4 & 7 & 3,57 \\
\hline 6 & Biaya jasa & 0 & 1 & 1 & 5 & 7 & 3,57 \\
\hline 7 & Kualitas jasa telekomunikasi & 0 & 0 & 2 & 5 & 7 & 3,71 \\
\hline 8 & Keberadaan material bahan baku & 0 & 3 & 2 & 2 & 7 & 2,86 \\
\hline 9 & Biaya pengadaan material/bahan baku & 0 & 5 & 2 & 0 & 7 & 2,29 \\
\hline 10 & Kualitas bahan baku & 0 & 1 & 3 & 3 & 7 & 3,29 \\
\hline 11 & Kualitas kehidupan lingkungan kerja & 0 & 1 & 3 & 3 & 7 & 3,29 \\
\hline \multirow[t]{2}{*}{12} & Kondisi lingkungan kerja & 0 & 2 & 1 & 4 & 7 & 3,29 \\
\hline & KONDISI DEMAND & & & & & & \\
\hline 1 & Perluasan pasar domestik & 0 & 0 & 6 & 1 & 7 & 3,14 \\
\hline 2 & Perluasan pasar ekspor & 0 & 4 & 1 & 2 & 7 & 2,71 \\
\hline 3 & $\begin{array}{l}\text { Kapasitas pengembangan demand untuk } \\
\text { produk baru }\end{array}$ & 0 & 1 & 5 & 1 & 7 & 3,00 \\
\hline 4 & $\begin{array}{l}\text { Daya tanggap terhadap perubahan dan } \\
\text { kebaruan }\end{array}$ & 0 & 1 & 2 & 4 & 7 & 3,43 \\
\hline 5 & Lingkungan Bisnis & 0 & 0 & 4 & 3 & 7 & 3,43 \\
\hline 6 & Kualitas dan reliabilitas dari produk dan jasa & 0 & 1 & 4 & 2 & 7 & 3,14 \\
\hline 7 & Kesadaran keberlanjutan produk dan support & 0 & 2 & 2 & 3 & 7 & 3,14 \\
\hline \multirow[t]{2}{*}{8} & Etika bisnis yang kuat & 0 & 0 & 3 & 4 & 7 & 3,57 \\
\hline & $\begin{array}{l}\text { STRATEGI, STRUKTUR } \\
\text { PERUSAHAAN }\end{array}$ & & & & & & \\
\hline 1 & $\begin{array}{l}\text { Keberadaan perusahaan asing dan joint } \\
\text { venture }\end{array}$ & 0 & 2 & 1 & 4 & 7 & 3,29 \\
\hline 2 & Kelenturan dari sistem produksi & 0 & 1 & 1 & 5 & 7 & 3,57 \\
\hline 3 & Kolaborasi perusahaan dan industri yang kuat & 0 & 2 & 4 & 1 & 7 & 2,86 \\
\hline 4 & $\begin{array}{l}\text { Pengembangan bersama dalam pengetahuan } \\
\text { industri }\end{array}$ & 0 & 0 & 2 & 4 & 7 & 3,14 \\
\hline 5 & Kepemimpinan nasional dan internasional & 0 & 4 & 4 & 0 & 7 & 2,86 \\
\hline 6 & Keterlibatan masyarakat dan kewirausahaan & 0 & 1 & 6 & 1 & 7 & 3,43 \\
\hline 7 & Orientasi Teknologi & 0 & 0 & 3 & 4 & 7 & 3,57 \\
\hline \multirow[t]{2}{*}{8} & Aplikasi teknologi tinggi dalam perusahaan & 0 & 0 & 4 & 3 & 7 & 3,43 \\
\hline & INDUSTRI PENDUKUNG YANG BERKAITAN & & & & & & \\
\hline 1 & Rantai Suplai & 0 & 0 & 3 & 4 & 7 & 3,57 \\
\hline 2 & Kekuatan jasa pendukung bisnis lokal & 0 & 1 & 4 & 2 & 7 & 3,14 \\
\hline 3 & Daya tanggap jasa pendukung lokal & 0 & 0 & 6 & 1 & 7 & 3,14 \\
\hline 4 & Kualitas jasa pendukung lokal & 0 & 0 & 7 & 0 & 7 & 3,00 \\
\hline
\end{tabular}

Sumber: Hasil survey, 2015 
Pada komponen faktor kondisi, atribut "ketersediaan tenaga kerja terampil" merupakan atribut paling penting. Urutan selanjutnya yang berpengaruh adalah kemampuan manajerial kemudian atribut kualitas jasa telekomunikasi. Pada komponen kondisi demand, atribut yang paling berpengaruh adalah etika bisnis yang kuat, kemudian atribut daya tanggap terhadap perubahan dan kebaruan dan lingkungan bisnis. Pada komponen strategi, struktur dan rivalry perusahaan, atribut yang paling berpengaruh adalah kelenturan dari sistem produksi dan orientasi teknologi, kemudian atribut aplikasi teknologi tinggi dalam perusahaan. Pada komponen industri pendukung yang berkaitan, atribut "rantai suplai" merupakan atribut yang paling berpengaruh.

Faktor eksternal yang mendukung aglomerasi industri ICT adalah infrastruktur yang maju, aksesibitas jalan, airport dan transportasi publik yang terpercaya, infrastruktur yang dikembangkan dengan baik seperti koneksi internet dan telepon yang handal, infrastruktur pendidikan yang unggul. Universitas dan sekolah yang baik memegang peranan penting; emampuan pembiayaan; masyarakat yang kreatif dan memiliki jiwa entrepreneurship; perangkat hukum yang baik dalam melindungi hak kekayaan intelektual serta kepastian hukum perpajakan; dan jaringan yang kuat dalam aspek pemasaran (Hansen \& Serin, 2010) Berdasarkan hal tersebut di atas maka, identifikasi yang dilakukan untuk melihat kondisi lingkungan eksternal meliputi tujuh komponen tersebut. Kondisi eksternal yang dilihat berdasarkan ketujuh komponen tersebut diatas secara nasional diperoleh dari data World Economic Forum (2015) dan data World Bank (2015). Sedangkan untuk data yang merupakan kondisi lokal di Kota Cimahi diperoleh dari Badan Pusat Statistik.

Faktor-faktor eksternal yang mempengaruhi daya saing industri telematika/ICT diperoleh dari data sekunder yang berasal dari berbagai sumber. Dari hasil identifikasi faktor yang mempengaruhi, kemudian dipilih faktor yang dominan. Faktor-faktor eksternal yang merupakan aspek yang dominan pada industri telematika di Kota Cimahi adalah: infrastruktur fisik, berupa adanya prasarana jalan kereta api, infrastruktur ICT, yaitu bahwa seratus persen penduduk terlayani oleh jaringan telepon selular, infrastruktur pendidikan: yaitu kualitas pendidikan menengah yang relatif baik dan adanya Akademi Komunitas bidang telematika/ ICT, kemampuan pembiayaan: yaitu adanya kemudahan akses pinjaman; dan perangkat hukum: berupa efisiensi pengeluaran pemerintah untuk biaya kebijakan dan, adanya regulasi yang mengatur tentang industri ICT/ telematika

\section{Tabel 3. Faktor Internal dan Eksternal Industri Telematika/ICT di Kota Cimahi}

\begin{tabular}{|c|c|c|}
\hline No & Faktor & Keterangan \\
\hline 1. & Ketersediaan tenaga kerja terampil & Faktor internal \\
\hline 2. & Kemampuan manajerial & Faktor internal \\
\hline 3. & Kualitas jasa telekomunikasi & Faktor internal \\
\hline 4. & Etika bisnis & Faktor internal \\
\hline 5. & Daya tanggap terhadap perubahan dan kebaruan & Faktor internal \\
\hline 6. & Lingkungan bisnis & Faktor internal \\
\hline 7. & Kelenturan dari sistem produksi & Faktor internal \\
\hline 8. & Orientasi Teknologi & Faktor internal \\
\hline 9. & Aplikasi teknologi tinggi dalam perusahaan & Faktor internal \\
\hline 10. & Rantai suplai & Faktor internal \\
\hline 11. & Kualitas transportasi kereta api & Faktor eksternal \\
\hline 12. & Jaringan telepon selular & Faktor eksternal \\
\hline 13. & Kualitas pendidikan menengah & Faktor eksternal \\
\hline 14. & Adanya akademi komunitas & Faktor eksternal \\
\hline 15. & Adanya kemudahan akses untuk pinjaman & Faktor eksternal \\
\hline 16. & Efisiensi biaya pemerintah untuk regulasi & Faktor eksternal \\
\hline 17. & Regulasi yang mengatur industri ICT/ telematika & Faktor eksternal \\
\hline
\end{tabular}

Sumber: Hasil survei, 2015 
Aspek kawasan dalam pengembangan industri telematika/ICT dalam penelitian ini lebih fokus pada lokasi kota yang menjadi objek penelitian. Hasil identifikasi untuk faktor internal dan eksternal dari industri telematika/ICT di Kota Cimahi disajikan pada Tabel 3.

\section{Identifikasi Faktor Kunci dalam Pengembangan Kawasan Industri Telematika/ICT di Kota Cimahi}

Faktor-faktor kunci dalam pengembangan kawasan industri telematika/ICT diperoleh dari hasil analisis pengaruh antar faktor. Seluruh faktor dianalisis pengaruh antar faktornya dengan cara pemberian nilai. Penilaian untuk tidak ada pengaruh antar faktor adalah 0 (nol), untuk pengaruh kecil bernilai 1 (satu), untuk pengaruh sedang bernilai 2 (dua) dan pengaruh yang kuat bernilai 3 (tiga). Hasil analisis pengaruh antar faktor disajikan pada Gambar 3.

Analisis antar faktor berdasarkan tingkat kepentingan faktor-faktor yang berpengaruh menghasilkan faktor kunci. Faktor kunci tersebut adalah faktor yang berada pada kuadran dengan tingkat ketergantungan dan pengaruh yang tinggi/ kuat (nilai lebih besar dari 1). Berdasarkan hasil analisis antar factor tersebut, faktor kunci yang terpilih adalah: (1) Kualitas jasa telekomunikasi; (2) Ketersediaan tenaga kerja terampil; (3) Daya tanggap terhadap perubahan dan kebaruan; (4) Etika bisnis dan (5) Regulasi yang mengatur industri ICT/telematika

Dari faktor-faktor kunci yang terpilih tersebut, kemudian dibuat keadaan yang mungkin terjadi. Hasil penyusunan keadaan setiap faktor kunci disajikan pada Tabel 4.

Berdasarkan Tabel 4 tampak bahwa faktor kunci yang pertama adalah "kualitas jasa telekomunikasi" yang akan mempunyai keadaan makin baik, tetap atau makin buruk. Faktor kedua adalah "ketersediaan tenaga kerja terampil" yang memiliki keadaan makin banyak, tetap atau makin sedikit. Faktor kunci ketiga yaitu "daya tanggap terhadap perubahan dan kebaruan" mempunyai keadaan makin kuat, tetap atau makin lemah. Faktor kunci keempat adalah "etika bisnis", mempunyai keadaan makin baik, tetap atau makin buruk. Faktor kunci terakhir adalah "regulasi yang mengatur industri ICT/telematika", dengan keadaan makin baik, tetap atau makin buruk.

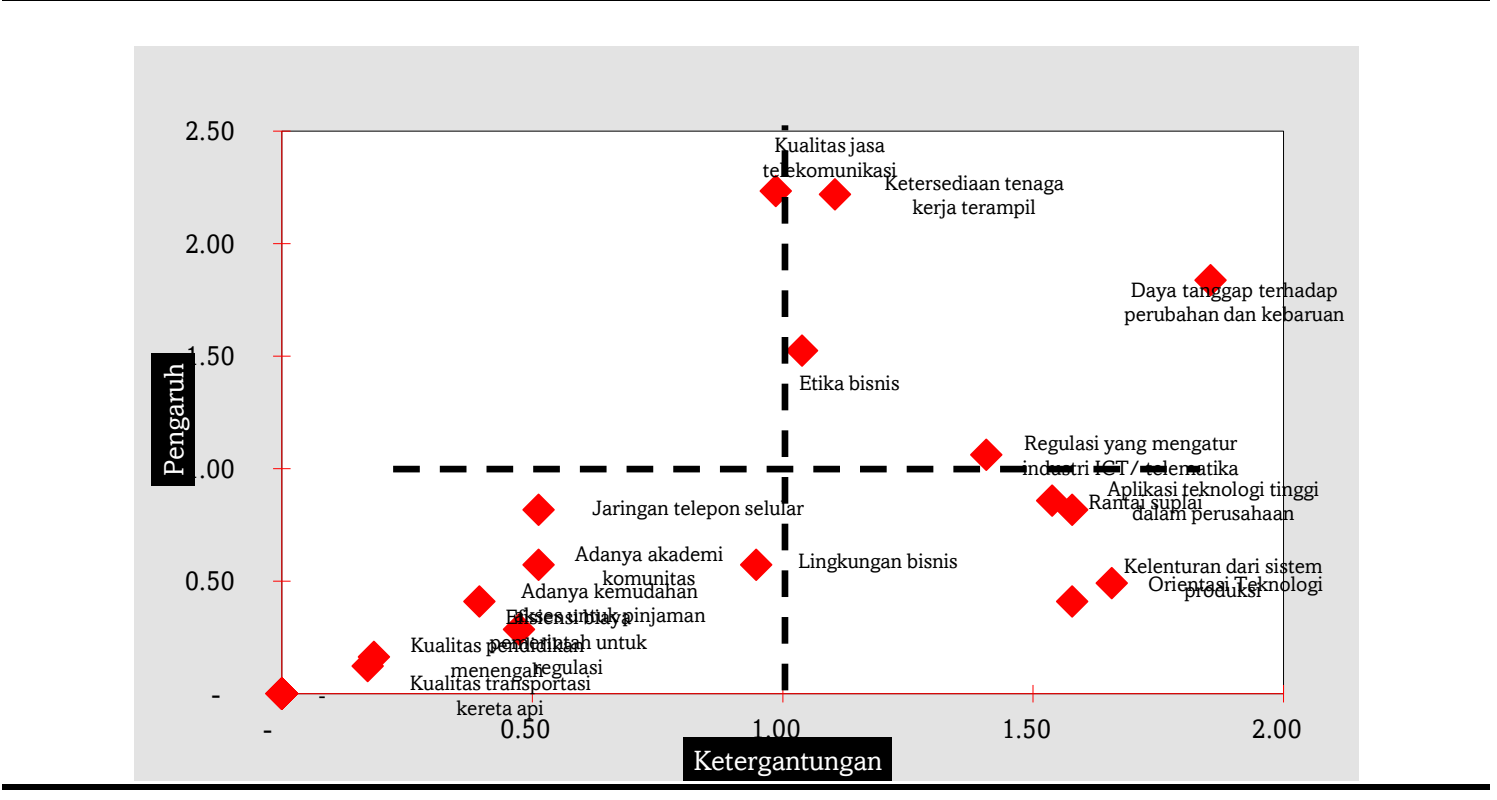

Gambar 3. Pengaruh Antar Faktor dalam Pengembangan Kawasan Industri Telematika/ICT di Kota Cimahi 
Tabel 4. Keadaan setiap faktor kunci untuk Pengembangan Industri ICT/ Telematika di Kota Cimahi

\begin{tabular}{llll}
\hline No & \multicolumn{1}{c}{ Faktor } & \multicolumn{1}{c}{ Keadaan yang mungkin terjadi } & \multicolumn{1}{c}{ Notasi } \\
\hline 1. & Kualitas jasa telekomunikasi & makin baik (A), tetap (B) atau makin buruk (C) & 1A, 1 B, 1C \\
2. & $\begin{array}{l}\text { Ketersediaan tenaga kerja } \\
\text { terampil }\end{array}$ & $\begin{array}{l}\text { makin banyak (A), tetap (B) atau makin sedikit } \\
\text { (C) }\end{array}$ & 2A, 2B, 2C \\
3. & $\begin{array}{l}\text { Daya tanggap terhadap } \\
\text { perubahan dan kebaruan }\end{array}$ & makin kuat (A), tetap (B) atau makin lemah (C) & 3A, 3B, 3C \\
4. & $\begin{array}{l}\text { Etika bisnis } \\
\text { Regulasi yang mengatur } \\
\text { industri ICT/telematika }\end{array}$ & makin baik (A), tetap (B) atau makin buruk (C) & 4A, 4B, 4C \\
& makin baik (A), tetap (B) atau makin buruk (C) & 5A, 5B. 5C \\
\hline
\end{tabular}

Sumber: Hasil analisis, 2016

Selanjutnya berdasarkan keadaan dari faktor kunci, disusun skenario yang mungkin terjadi. Skenario disusun dari skenario paling optimis sampai paling pesimis untuk pengembangan kawasan industri telemika dalam upaya mendorong daya saing regional. Cara penentuan skenario adalah pemberian nilai/ skor. Hasil pemilihan skenario disajikan pada Tabel 5.

Tabel 5. Skenario Pengembangan Industri ICT/ Telematika di Kota Cimahi Berdasarkan Faktor Kunci

\begin{tabular}{|c|c|c|c|c|c|}
\hline \multirow{2}{*}{ No } & \multirow{2}{*}{\multicolumn{2}{|c|}{ Skenario }} & \multirow{2}{*}{ Urutan Faktor } & \multicolumn{2}{|c|}{ Nilai } \\
\hline & & & & Total & Persentase \\
\hline 1 & $\begin{array}{l}\text { Sangat optimis untuk } \\
\text { regional }\end{array}$ & memiliki daya saing di tingkat & 1A-2A-3A-4A-5A & 3 & 13 \\
\hline 2 & Optimis untuk berdaya & saing di tingkat regional & 1B-2B-3A-4A-5A & 14 & 47 \\
\hline 3 & Agak optimis untuk ber & rdaya saing di tingkat regional & $1 B-2 B-3 B-4 A-5 A$ & 6 & 20 \\
\hline 4 & Kondisi tetap & & 1B-2B-3B-4B-5B & 3 & 10 \\
\hline 5 & Kondisi semakin tidak b & berdaya saing di tingkat regional & $1 C-2 C-3 C-4 C-5 C$ & 3 & 10 \\
\hline & & Total & & 30 & 100 \\
\hline
\end{tabular}

Sumber: Hasil analisis, 2016

Skenario yang paling banyak dipilih adalah skenario optimis untuk berdaya saing di tingkat regional. Skenario ini dengan keadaan "kualitas jasa telekomunikasi" yang "tetap"; keadaan dari faktor kunci "ketersediaan tenaga kerja terampil" yang "tetap"; keadaan "daya tanggap terhadap perubahan dan kebaruan" yang "makin kuat”; keadaan "etika bisnis" yang "makin baik"; dan "regulasi yang mengatur industri ICT/ telematika" yang makin baik.

Hasil penelitian untuk mengidentifikasi faktor daya saing dari industri telematika/ICT di Cimahi relatif sama dengan hasil penelitian di Bangladesh. Menurut Al Mamun, Zayed dan Hossain (2013), faktor daya saing dari industri telematika/ ICT di Bangladesh adalah sumberdaya manusia (SDM) dalam aspek biaya tenaga kerja dan kelompok umur dari pekerja. Hasil ini hampir sama dengan hasil penelitian di India. Hasil penelitian di India menurut Balatchandirane (2007) kualitas sumberdaya manusia merupakan salah satu faktor dari pengembangan kawasan industri telematika di Bangalore, Hyderabad, India.

Regulasi menjadi salah satu faktor kunci untuk pengembangan kawasan industri telematika/ICT, yang sejalan dengan hasil evaluasi kebijakan untuk pengembangan industri kreatif di perkotaan. Menurut Liu dan Chiu (2017) bahwa kapabilitas, kerjasama bidang industri, inkubasi inovasi dan integrasi antara pemerintah, akademisi dan industri merupakan dasar-dasar yang penting untuk kota-kota mengembangkan industri kreatif. Selain itu, riset dan pengembangan serta pengklastrean, pelatihan, konsultasi dan bantuan pemasaran serta jaringan merupakan aspek yang perlu dikembangkan. 


\section{KESIMPULAN}

Karakteristik umum dari industri telematika di Kota Cimahi adalah usia perusahaan masih relatif muda yaitu kurang dari sepuluh tahun. Jumlah tenaga kerja dari perusahaan industri telematika relatif sedikit yaitu berkisar 4 sampai dengan 11 orang. Produk yang dihasilkan dari industri telematika yang ada di Kota Cimahi adalah animasi, film dan sistem informasi. Jadi kompetensi inti dari industri telematika/ ICT di Kota Cimahi adalah animasi, film dan sistem informasi.

Faktor internal yang mempengaruhi daya saing industri telematika di Cimahi adalah (1) ketersediaan tenaga kerja terampil; (2) kemampuan manajerial; (3) kualitas jasa telekomunikasi; (4) etika bisnis; (5) daya tanggap terhadap perubahan dan kebaruan; (6) lingkungan bisnis; (7) kelenturan dari sistem produksi; (8) orientasi teknologi; (9) aplikasi teknologi tinggi dalam perusahaan; dan (10) rantai suplai. Faktor eksternal dari industri telematika/ ICT di Kota Cimahi yang dapat mempengaruhi daya saing di tingkat regional adalah: (1) kualitas transportasi kereta api, (2) jaringan telepon selular, (3) kualitas pendidikan menengah, (4) adanya akademi komunitas (5) adanya kemudahan akses untuk pinjaman, (6) efisiensi biaya pemerintah untuk regulasi, dan (7) regulasi yang mengatur industri ICT/ telematika.

Berdasarkan hasil analisis antar faktor untuk pengembangan kawasan industri telematika di Kota Cimahi, faktor kunci yang dapat dikembangkan untuk mendorong daya saing regional adalah: (1) Kualitas jasa telekomunikasi; (2), Ketersediaan tenaga kerja yang terampil (3) Daya tanggap terhadap perubahan dan kebaruan, (4) Etika bisnis, dan (5) Regulasi yang mengatur industri ICT/telematika.

Skenario untuk pengembangan industri telematika berdasarkan analisis prospektif untuk Kota Cimahi adalah dengan skenario optimis. Pengembangan industri telematika dalam upaya meningkatkan daya saing regional untuk Kota Cimahi adalah dengan keadaan "kualitas jasa telekomunikasi" yang "tetap"; keadaan dari faktor kunci "ketersediaan tenaga kerja terampil" yang "tetap"; keadaan "daya tanggap terhadap perubahan dan kebaruan" yang "makin kuat"; keadaan "etika bisnis" yang "makin baik"; dan "regulasi yang mengatur indsutri ICT/ telematika” yang makin baik.

\section{UCAPAN TERIMA KASIH}

Ucapan terima kasih disampaikan kepada Direktorat Riset dan Pengabdian Masyarakat, Direktorat Jenderal Penguatan Riset dan Pengembangan, Kementerian Riset, Teknologi dan Pendidikan Tinggi yang telah memberikan dana untuk penelitian ini melalui skema Hibah Bersaing/ Penelitian Produk Terapan tahun 2015-206. Terima kasih juga disampaikan kepada Bapak Rudi Suteja dari Cimahi Creative Association (CCA) atas bantuan dan dukungan pada penelitian ini.

\section{DAFTAR PUSTAKA}

Al Mamun, MA; NA Zayed and MS Hossain. (2013). Using Porter's Diamond to Determine the Condition of ICT in a Developing Country: A Study on Bangladesh. International Journal of Business and Management Review. 1(3):138-150

Anandhita, V.H. (2015) Analisis Ekosistem TIK Indonesia dalam Mendorong Perkembangan Indutri Lokal dan Ekonomi Kreatif. Jurnal Penelitian Pos dan Informatika. 5(1): 49-64

[APJII] Asosiasi Penyelenggara Jasa Internet Indonesia dan [Puskakom] Pusat Kajian Komunikasi Universitas Indonesia. (2015). Profil Pengguna Internet Indonesia Tahun 2014. Jakarta: APJII. http://www.apjii.or.id/read/article/statistik/305/profil-pengguna-internet-indonesia-2014.html [tanggal akses 24 Augustus 2015]

Badan Pusat Statistik Kota Cimahi. (2015). Cimahi dalam Angka. Cimahi: Badan Pusat Statistik Kota Cimahi. 
Balatchandirane, G. (2007). IT Clusters in India. Discussion paper No.85. Institute of Developing Economies.

Godet, M. (2000). The art of scenario and strategic planning: tools and pitfalls. Technological Forecasting and Social Change 65: 3-22.

Hansen, PA \& G. Serin. (2010). The European ICT Clusters- an overview of selected ICT clusters in Europe. http://rucforsk.ruc.dk/site/files/32956338/the_european_ict_clusters_web_0.pdf [diakses tanggal 15 Desember 2013]

International Telecommunication Union (ITU). (2016). ICT Fact and Figures 2016. http://www.itu.int/en/ITUD/Statistics/Documents/facts/ICTFactsFigures2016.pdf [tanggal askses 27 Juli 2016]

Kementerian Koordinator Bidang Perekonomian. (2011). Masterplan Percepatan dan Perluasan Pembangunan Ekonomi Indonesia. Jakarta: Kementerian Koordinator Bidang Perekonomian.

Lengyel, I. 2003. Economic Growth and Competitiveness of Hungarian Regions. Paper prepared for "Reinventing Regions in the Global Economy" RSA Conference, 2003. http://www2.eco.uszeged.hu/region_gazdfejl_szcs/pdf/Economic_growth_and_competitiveness_of_Hungarian_regions.p df [tanggal askes 5 Mei 2016].

Liu, Y.Y. \& Y.H. Chiu. (2017). Evaluation of the Policy of the Creative Industry for Urban Development. Sustainability 2017, 9, 1009; doi:10.3390/su9061009

Lucas, M; A.Sands \& DA Wolfe. 2009. Regional Cluster in Global Industry: ICT Cluster in Canada. European Planning Studies. 17 (2):189-209

Martin, RL. (2013). A Study on Factors of Regional Competitiveness. University of Cambridge. http://ec.europa.eu/regional_policy/sources/docgener/studies/pdf/3cr/competitiveness.pdf [tanggal akses 1 Desember 2013]

[Mastel] Masyarakat Telekomunikasi. (2005). Cetak Biru Telematika 2005-2015. Buku II Bidang Manufaktur.

Mulyadi, D. (2013). Peningkatan Daya Saing Industri Daerah Melalui Pengembangan Pusat-pusat Pertumbuhan Industri. Rapat Kerja Kementerian Perindustrian 22 Mei 2013.

Porter, M. (1990). The Competitive Advantage of Nation. Harvard Bussiness Review, March April 1990.

The World Bank. (2016). The Little Data Book on Information and Communication Technology 2015. Washington: The World Bank Publishing and Knowledge Division.

World Economic Forum. (2015). The Global Competitiveness Report 2015-2016. Geneva: World Economic Forum 